\title{
Genioplasty and Mandibular Implants
}

\author{
Tom Shokri, MD ${ }^{1}$ Mattie Rosi-Schumacher, MD ${ }^{2}$ Laura Petrauskas, MD ${ }^{3}$ David Chan, MD FACS ${ }^{3}$ \\ Yadranko Ducic, MD FRCS(C), FACS ${ }^{1}$
}

1 Otolaryngology and Facial Plastic Associates, Fort Worth, Texas

${ }^{2}$ Department of Otolaryngology, Jacobs School of Medicine and

Address for correspondence Yadranko Ducic, MD, FRCS(C), FACS, Biomedical Sciences, University at Buffalo, The State University of New York, Buffalo, New York

3 Section of Otolaryngology-Head \& Neck Surgery, Department of Otolaryngology and Facial Plastic Surgery Associates, 923Pennsylvania Avenue, Suite 100, Fort Worth, TX 76104 (e-mail: yducic@sbcglobal.net).

Surgery, University of Chicago, Chicago, Illinois

Facial Plast Surg 2021;37:709-715.
Abstract
Keywords
- genioplasty
- alloplastic implants
- facial implants
- sliding genioplasty
- mandibular implants

Genioplasty is a useful technique employed for both aesthetic and, in the case of obstructive sleep apnea, functional purposes. Mandibular implants similarly represent a powerful tool in the facial surgeons armamentarium. Herein, we review relevant anatomy, patient evaluation, and various techniques employing both alloplastic augmentation and osseous modification of the mandible.

\section{Anatomical Considerations}

Genioplasty can address both functional and aesthetic issues and can involve either augmentation via implants or osseous genioplasty via osteotomy and adjustment of chin position. The chin is essential in determining facial profile and is an important factor when assessing attractiveness. ${ }^{1,2}$ The mandible provides shape to the lower third of the face, positions the mentum and lower lip, and establishes a border between the face and neck. It supports the mandibular dentition, masticator muscles, and positions the tongue. ${ }^{3}$ The chin is defined superiorly by the labiomental crease, laterally by the oral commissures, and inferiorly by the submental-cervical crease. ${ }^{4,5}$ Understanding the anatomy of the chin and the mandible as well as how to appropriately analyze them in the facial profile is vital to success in genioplasty.

\section{Innervation}

The main innervation to the mandible is derived from the inferior alveolar nerve, a division of the trigeminal nerve, and is the third branch that runs in the mandibular canal, and then divides into the dental nerve that continues as the incisive ranch and goes on to innervate the canines and incisors and the mental nerve that exits the mental foramen providing sensation to region of the chin and lower lip. ${ }^{6}$ The mental foramen typically lies parallel to the canines $1.5 \mathrm{~cm}$ above the lower aspect of the mandible. Osteotomies should be performed 5 to $6 \mathrm{~mm}$ below the most inferior aspect of the mental foramen to avoid injury to the inferior alveolar nerve. ${ }^{7,8}$ In addition, it is theorized that there are cutaneous branches from the mylohyoid that supply sensation to the chin. $^{9}$

\section{Musculature}

Numerous muscles have attachments to the mandible that involve mastication, swallowing, respiration, support for the hyoid, and tongue and lip movement. The muscles of mastication functionally control the movement of the jaw. Muscles that function to elevate the mandible include temporalis, masseter, and the medial pterygoid muscles, whereas the lateral pterygoids lower the mandible. The lateral ramus serves as the attachment site for the masseter and the pterygoids attach to the medial surface. ${ }^{5,10,11}$ These muscular attachments should attempt to be preserved when performing augmentation to the mandible and jawline. Notably, one must preserve function of the mentalis muscles when performing genioplasty. These paired muscles arise from the anterior aspect of the mandible and insert onto the soft published online

September 16, 2021
Issue Theme Skeletal Facial Plastic Surgery; Guest Editor: Yadranko Ducic, $M D, F R C S(C)$, FACS (c) 2021. Thieme. All rights reserved. Thieme Medical Publishers, Inc., 333 Seventh Avenue, 18th Floor, New York, NY 10001, USA
DOI https://doi.org/ 10.1055/s-0041-1735307. ISSN 0736-6825. 
tissue of the chin. They function to elevate the skin of the chin, thereby indirectly elevating the lip. Lack of preservation of the muscular attachments of the mentalist muscles during genioplasty may result in lower lip incompetence and chin ptosis. $^{12-14}$

\section{Analysis}

Prior to consideration of genioplasty one must assess facial symmetry. Photographs of the patients in frontal, lateral, and oblique positions should be obtained. With more complex cases, there should be consideration of imaging including panoramic radiograph (panorex) to evaluate mandibular anatomy, tooth root positioning, and position of the inferior alveolar nerve. If considering osseous genioplasty, cephalometric radiographs in posteroanterior and lateral views are recommended to be obtained. ${ }^{4}$

\section{Vertical Facial Height}

Evaluation of the chin and lower facial unit in comparison to the rest of the face can be done by dividing the face into thirds. The lower third consists of the chin and lips and extends from subnasale to gnathion. If the distance is greater than one-third of the facial subunits, it is classified as vertical macrogenia, and if the distance is less, it is classified as vertical microgenia. The lower third can be further subdivided by subnasale to stomion of upper lip and from the stomion to the menton. ${ }^{14}$

When assessing a patient's profile and facial height, it is important to consider the depth of the labiomental fold, the indentation between the lower lip and lower mandible. This fold is typically $4 \mathrm{~mm}$ deep in women and $6 \mathrm{~mm}$ deep in men. Patients with decreased lower facial height tend to have deeper folds. In these patients, sagittal advancement of the mandible should be accompanied by vertical lengthening. Conversely, patients with increased lower facial height often have shallow folds, thus sagittal advancement should be accompanied by vertical shortening to achieve ideal aesthetics. $^{7,15}$

\section{Cervical-Mental Angle}

The angle of the chin to the neck or cervicomental angle should be 105 to 120 degrees with the vertex at the hyoid and lines extending to gnathion and to the sternal notch. This angle has impact on the how the chin appears in relation to other facial structures and is an important consideration prior to genioplasty.

\section{Chin Projection}

Numerous methods have been proposed in the assessment of ideal chin projection, likely due to lack of one universal objective measure and resultant intrarater, interrater, and retest variability. ${ }^{16,17}$ However, familiarity with these methods may be useful, particularly to the novice surgeon. A simple method by which to assess chin projection is Reidel's line. In a balanced face, it is a line that projects from the most prominent portion of the upper and lower lips to the pogonion (the anterior most part of the chin). Observation of projection anteriorly or posteriorly indicates horizontal macrognathia or micrognathia., ${ }^{4,7}$ Ricketts analysis states that a line drawn from the pogonion to the upper lip should be $4 \mathrm{~mm}$ posterior to this line and the lower lip should be $2 \mathrm{~mm}$ posterior to the line. ${ }^{18} \mathrm{~A}$ common criticism of this technique is its overreliance on the nasal tip. Steiner analysis uses a line from the columellar inflection point to the pogonion with the upper and lower lips also meeting the line. However, it is similarly criticized for its heavy reliance on lip positioning, which again varies on an individual basis. ${ }^{14,19}$

Gonzalez-Ulloa zero meridian line utilizes the Frankfort plane, which extends horizontally from upper aspect of the external auditory meatus to the lower ridge of the orbit, and is intersected by a perpendicular vertical line from the nasion. Ideally, the chin should meet this line, and anterior advancement is considered protrusion and if the chin is posterior to the line, it is considered retrusion. ${ }^{20}$

The Goode method traces a line from the nasal ala and suggests that the pogonion should be on the line or just posterior to it. ${ }^{16,21,22}$

Merrifield $\mathrm{Z}$ angle measures a line tangential to the Frankfurt horizontal extending from pogonion to the lip that protrudes more, the ideal angle is between 75 and 85 degrees. ${ }^{23}$ All the aforementioned techniques are subject to some subjective interpretation.

Lehan angle of facial complexity measures a line from glabella to subnasale, and then a line from the subnasale to the pogonion with an ideal angle of 12 degrees. $^{21}$

\section{Dental Occlusion}

Prior to proceeding with mandibular augmentation, it is important to assess dental occlusion as patients with type II or III angle occlusion may require osteotomies in addition to genioplasty, whereas patients with normal occlusion or class I can typically be treated with genioplasty alone. ${ }^{7}$

Although there are many aspects to consider in evaluation of the facial skeleton, a combined assessment provides multiple data points upon that one may hope to obtain an ideal outcome.

\section{Mandibular Implants}

There are currently two widely available types of alloplastic implants for the mandibular angle. These implants target two components of the mandibular angle: lengthening along the vertical dimension and widening within the lateral plane. Aside from their variability in dimensions, ideal implants should display the following features: configuration that emulates natural anatomical contour, immunologically inert, malleable and easily conformable, and modifiable. ${ }^{24-27}$ Silastic implants are the most commonly used alloplastic material and meet the aforementioned criteria. When implanted, this alloplastic material induces fibrosis of surrounding tissue with 


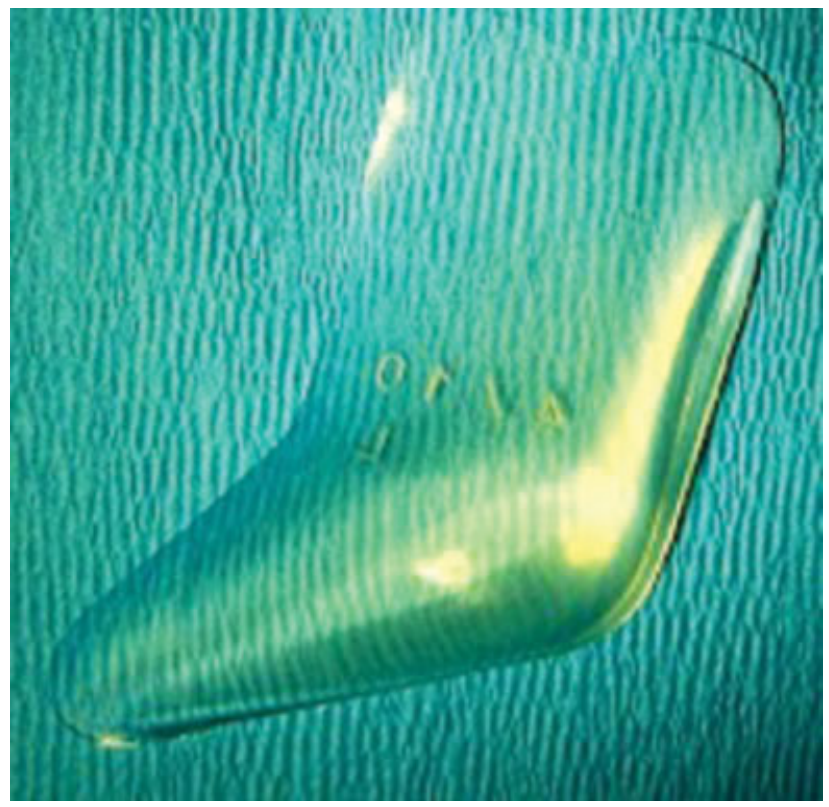

Fig. 1 Silastic angle implant. Reproduced with permission from Terino EO, Edwards MC. Customizing jawlines: the art of alloplastic premandible contouring. Facial Plast Surg Clin North Am. 2008;16 (1):99-122.

resultant capsule formation and fixation of the implant. However, if modification or revision surgery is required, open capsulotomy may be performed with removal or further contouring. ${ }^{28}$ Silastic implants are also biologically inert and resistant to infection (- Figs. $\mathbf{1}$ and $\mathbf{2}$ ). In stark contradistinction, porous implants, such as Medpor and Gore-Tex, or fenestrated implants have been shown to display increased rates of infection and are difficult to remove. ${ }^{28-30}$

Implant contour should reflect the patient's desired aesthetic outcome. In particular, preoperative assessment should include discussion with the patient regarding realistic outcomes and evaluation of the jaw angle width and length. A detailed medical history should include prior surgeries, such as sagittal split osteotomies, that may influence any pre-existing asymmetries along the jaw line. If a

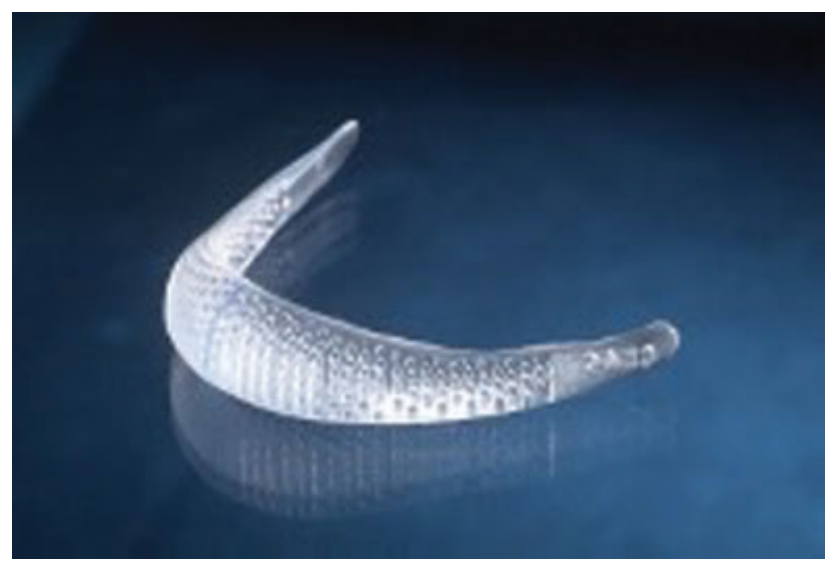

Fig. 2 Silastic chin implant. Reproduced with permission from Romo III T, Lanson BG. Chin augmentation. Facial Plast Surg Clin North Am. 2008;16(1):69-77. standard jaw angle implant is adequate to meet patient specific needs, custom designed jaw angle implants may be utilized. ${ }^{31,32}$

\section{Surgical Technique}

Several general principles should be implemented in implant augmentation of the mandible. Implants should be placed directly atop the mandibular bone, within a subperiosteal plane. This will facilitate adherence to the osseous skeleton via fibrous encapsulation. Adequate infiltration with local anesthetic will facilitate elevation of the soft tissue planes in atraumatic fashion. This is of paramount importance as adequate dissection within the premandibular space is required to accommodate implants. Blunt dissection should be employed when possible to avoid nerve and associated foramina.

Placement of angle implants may be accomplished via an intraoral approach through a posteriorly based vestibular incision. The outline of the jawline should be marked preoperatively to facilitate intraoperative assessment. The intraoral vestibular incision should be injected with $1 \%$ lidocaine with 1:100,000 epinephrine. External injection in a subperiosteal plane with elevation of underlying soft tissues may be particularly helpful in angle augmentation. Care must be taken to implement a transverse incision parallel to the border of the mandible and ascending ramus, leaving a $1 \mathrm{~cm}$ cuff of mucosa and buccinator muscle to facilitate closure. The buccal sensory neurovascular bundle may be encountered during the initial approach and should be retracted medially. Blunt dissection along the external oblique ridge in a subperiosteal plane should then be employed followed by wide undermining toward the posterior mandibular border. Dissection should then be carried in this plane superiorly to the coronoid notch, inferiorly to the border, and anteriorly along the inferior border. A broad pocket should be created to mitigate malpositioning of implant. Release of the ligamentous attachments along the inferior border of the mandible is particularly important for appropriate implant positioning. Care must be taken to prevent pterygomasseteric sling detachment that may result in retraction of the muscle laterally and externally with subsequent displacement of the implant with poor contour (-Figs. 3 and 4). Following placement of angle implants screw fixation should be performed to prevent migration.
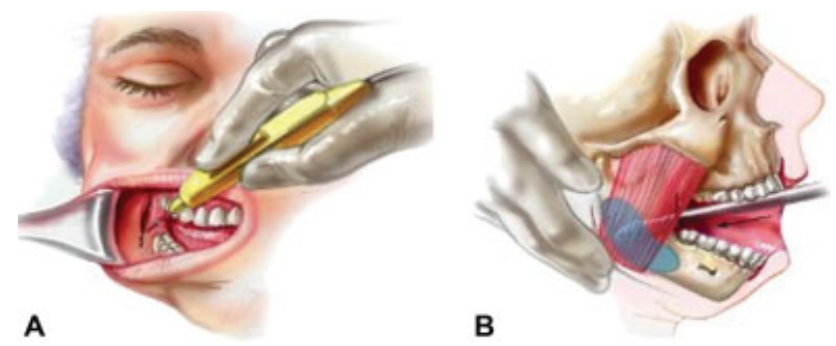

Fig. 3 (A) Intraoral vestibular approach to mandibular angle. (B) Dissection beneath masseter along posterior and inferior mandibular border. Reproduced with permission from Terino EO, Edwards MC. Customizing jawlines: the art of alloplastic premandible contouring. Facial Plast Surg Clin North Am 2008;16(1):99-122. 


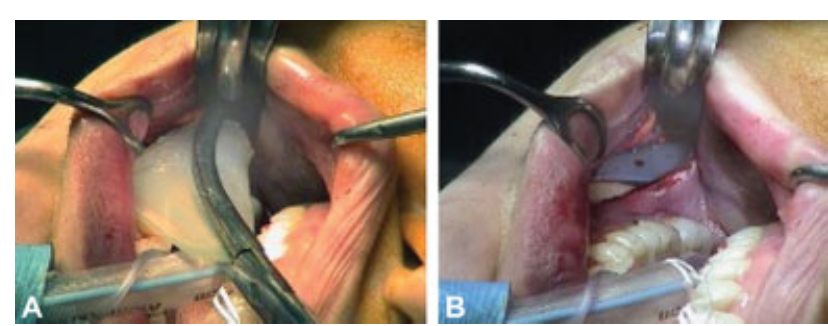

Fig. 4 (A) An posterior pocket created for appropriate positioning of angle implant. (B) Intraoral placement of angle implant. Reproduced with permission from Terino EO, Edwards MC. Customizing jawlines: the art of alloplastic premandible contouring. Facial Plast Surg Clin North Am 2008;16(1):99-122.

This is particularly important in implantation along the mandibular angle to prevent migration with masticatory forces. ${ }^{33,34}$ Screw fixation may be performed via an intraoral approach, particularly with utilization of a 90-degree screwdriver; however, below the external oblique ridge, the angle of the mandible makes screw engagement difficult. Alternatively, a percutaneous approach may be implemented to facilitate perpendicular screw engagement. Self-drilling, titanium screws (2-3 mm; Depuy Synthes, Paoli, PA) may be used followed by multilayered closure utilizing 3-0 Vicryl suture to reconstitute the muscular layer followed by either running or interrupted 3-0 Vicryl or 3-0 chromic suture for mucosal reapproximation. ${ }^{35}$

\section{Postoperative Care and Considerations}

Routine postoperative antibiotics should be employed in all patients with alloplastic mandibular augmentation. Consideration may be given to use of $0.12 \%$ chlorhexidine oral solution following all meals, in the morning, and prior to bed to promote oral hygiene following the first 2 to 3 weeks after surgery. Mild trismus may be encountered due to masseteric myositis secondary to instrumentation. This should be self-limited and patients may be placed on a soft diet in the first week following surgery. Range of motion exercises should be encouraged to prevent ankylosis and facilitate recovery. Patients should be counseled that postoperative edema may persist for 4 to 6 weeks and final aesthetic results may not be apparent until several months following intervention.

\section{Surgical Techniques in Alloplastic Chin Augmentation}

Chin augmentation may be more readily performed within the office under local anesthesia and mild oral sedation. However, surgeon experience and patient comfort should guide management particularly when the procedure is done in conjunction with rhinoplasty, submental liposuction, or platysmaplasty. A submental, transcutaneous, or intraoral approach may be utilized for appropriate implant placement. ${ }^{36-39}$ Both techniques have shown distinct advantages and disadvantages. Ultimately, surgeon and patient preference and goals should determine the chosen technique. A submental approach may be employed in cases in which adjuvant neck procedures, such as lipectomy or platysmaplasty, will be employed and results in minimal scarring that is well camouflaged within the submental crease.

When performing submental approach to the chin, midline structures including the central incisors, lips, chin, and thyroid cartilage should be marked preoperatively. A 1.5 to $2 \mathrm{~cm}$ incision is then designed within the existing submental crease and a skin incision made. Dissection is then performed until the anterior-inferior border of the mandible is encountered and exposed. Similar to description of the angle, a subperiosteal plane must be entered. A paramedian incision may then be made $1 \mathrm{~cm}$ along each side of the midline using monopolar electrocautery with creation of a subperiosteal pocket. Notably, dissection along the inferior mandibular border should not extend greater than $1 \mathrm{~cm}$ superiorly so as to avoid the mental foramina and injury to the mental nerve. Subperiosteal pockets should be made as small as possible initially and subsequently modified with placement of implant sizer and assessment of suitability. The appropriate implant is then placed within this pocket with the flange anchors first. Modifications to this implant can then be made based on patient aesthetics and the implant may be trimmed accordingly. The implant should then be secured to the adjacent periosteum using 3-0 nylon suture, monocortical self-drilling screws, or lag screws in the case of an autologous osseous implant. The incision is then closed in multilayered fashion as described previously with care to reapproximate the mentalis muscle.

Alternatively, the intraoral approach begins with a semicircular mucosal incision that is centered upon the inferior frenulum using either 15-blade or electrocautery. Electrocautery is then used to dissect through the submucosal plane reaching the periosteum. Paramedian periosteal incisions are again made $1 \mathrm{~cm}$ on either side of the midline with subsequent blunt elevation of a subperiosteal pocket utilizing freer or periosteal elevators. The pocket should be slightly larger than the implant or implant-sizer. The implant may then be secured with two midline monocortical self-tapping screws. The mentalis muscle is then carefully reapproximated, to prevent drooping of the lip, and the remainder of the incision closed in standard layered fashion following implant placement. Placement of the implant correctly within a subperiosteal plane will mitigate the risk of subsequent extrusion.

\section{Advancement Genioplasty}

While mandibular implants can achieve aesthetic goals, it is unable to offer any functional benefit for patients, particularly those with sleep apnea. ${ }^{40-44}$ Furthermore, alloplastic implants can be complicated by infection, chronic inflammation, extrusion, bone resorption, capsular contraction, displacement, and chin ptosis. ${ }^{40,45}$ Advancement genioplasty may also be more beneficial in patients with more complex deformities and yields more predictable and stable results. ${ }^{40,43,46}$ 


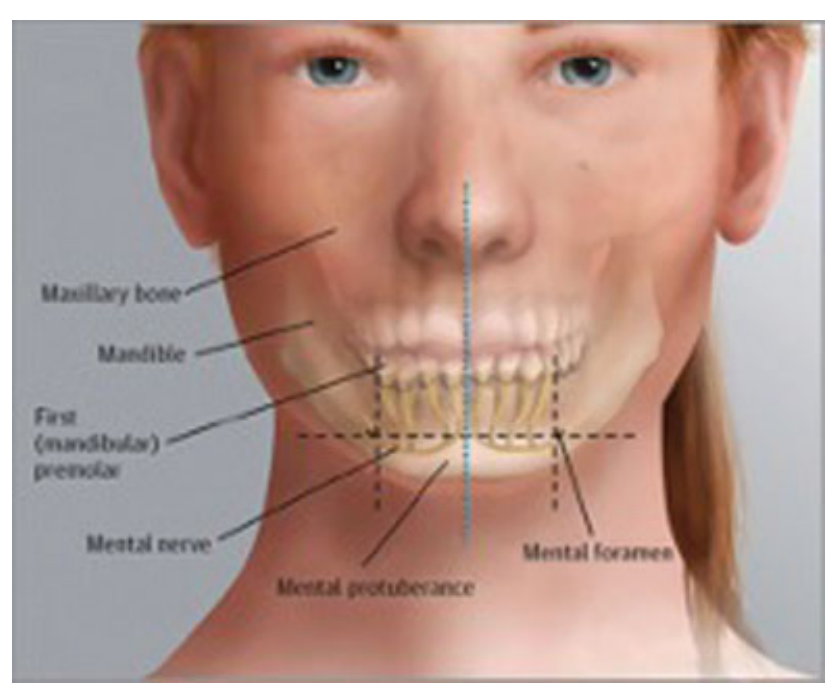

Fig. 5 Marking for osteotomies. Lateral boundary is marked by a vertical line dropped from the mental foramen. Horizontal boundary is marked inferior to tooth roots.

Advancement genioplasty via an external approach was first described by Hofer in 1942. An intraoral approach was subsequently described by various authors in the late 1950s. Improvement in rigid fixation techniques in the 1980s and beyond yielded improved results. Today, manipulation of the sliding segment allows for correction in the horizontal, vertical, and transverse dimensions making this technique versatile enough to address various chin abnormalities. $^{40,46,47}$ Various authors recommended osseous genioplasty due to its versatility, predictability, stability, and low complication rates. ${ }^{43,44,48-50}$ In addition to the aesthetic improvements of sliding genioplasty, various authors have also shown how it can be used to improve obstructive sleep apnea as well. ${ }^{4,51-54}$ In experienced hands, Gui et al showed that osseous genioplasty yielded no malunions or nonunions in their 500 patient cohort. ${ }^{48}$ Another particular concern is

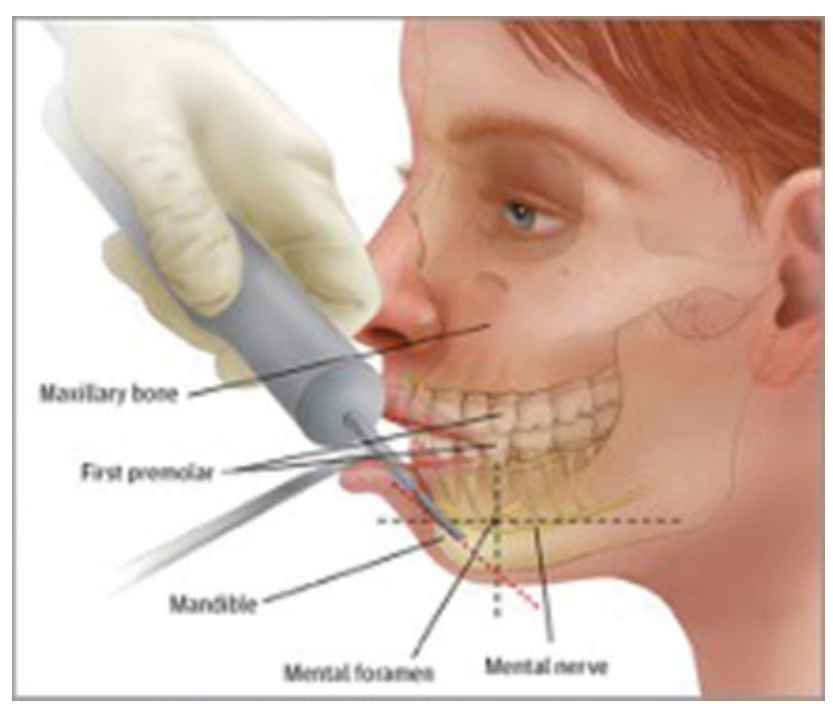

Fig. 6 Angulation of the saw mitigates mental nerve injury.

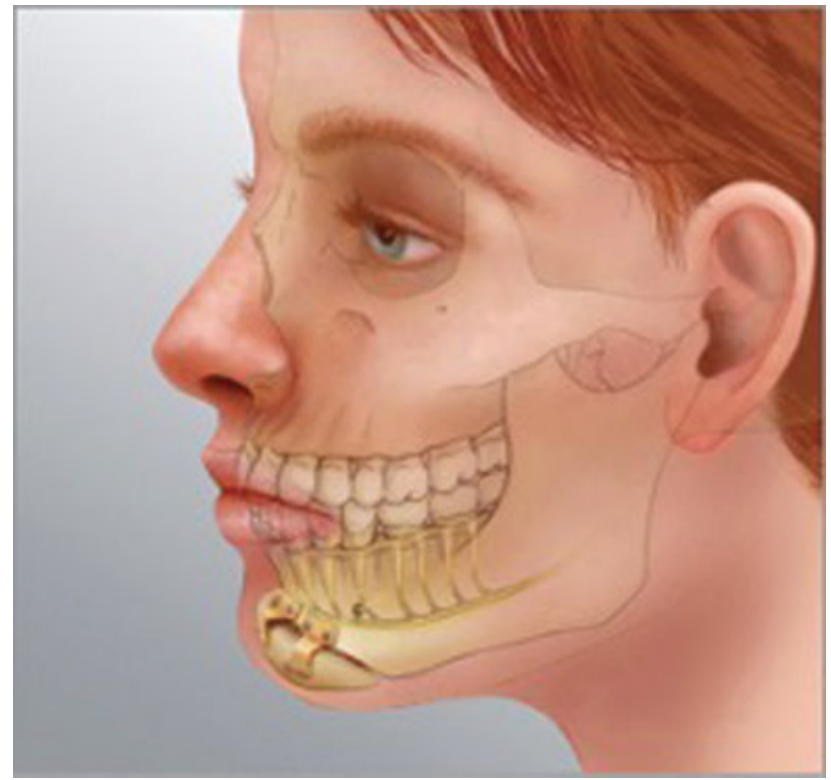

Fig. 7 Advancement and fixation of the mandible. Two-step plates are used to secure the advanced segment of the mandible.

injury to the mental nerve, with transient injury rates ranging between 9 and 100\%. ${ }^{55}$ Chan and Ducic, however, developed a technique that minimizes the mental nerve injury rate to $2.4 \%$ and yields consistent results. ${ }^{44}$ An incision is made in the gingivobuccal sulcus, making sure to leave at least a $1 \mathrm{~cm}$ cuff of tissue for closure. Dissection is carried through the mentalis muscle and extended to the subperiosteal plane. The mental foramen and neurovascular bundle are then identified laterally. The mentalis is left attached to the anterior aspect of the mandible to preserve blood supply, allow advancement of underlying musculature, and prevent chin ptosis. The boundaries of the osteotomy include a vertical line drawn through the mental foramen as it crosses the mandible laterally and inferiorly, with the superior boundary being just below the tooth roots (-Fig. 5). A reciprocating saw is used in an angulated fashion, directed from the superior aspect of the osteotomy toward the inferior border of the mandible, to protect the mental nerve, dentition, and prevent a noticeable step-off (-Fig. 6). The distal mandible is then advanced anteriorly. It should be noted that the distal inferior aspect of the mandible and the distal body of the mandible overlap are in apposition to facilitate osseous union. The two segments are then rigidly fixated with two-step plates, secured with monocortical screws (-Fig. 7). The wound is then thoroughly irrigated and closed in layers with reapproximation of the mentalis muscle and mucosa.

\section{Conclusion}

A variety of techniques have been reported in the literature and all appear to provide both aesthetic and functional benefit for patients. ${ }^{44,56-61}$ However, the facial plastic surgeon should implement a technique that has optimal and reproducible outcomes, while mitigating the risk of complications, in his or her hands. Although alloplastic implants are 
facile technique in chin augmentation, they incur the risk of infection, erosive osseous changes, and extrusion. Advancement genioplasty represents a reproducible, safe, and overall effective technique for the surgeon's armamentarium.

\section{Conflict of Interest}

None declared.

\section{References}

1 Keating CF. Gender and the physiognomy of dominance and attractiveness. Soc Psychol Q 1985;48:(01):61-70

2 Naini FB, Donaldson AN, McDonald F, Cobourne MT. Assessing the influence of chin prominence on perceived attractiveness in the orthognathic patient, clinician and layperson. Int J Oral Maxillofac Surg 2012;41(07):839-846

3 Spiegel JH, DeRosa J. In: Lalwani A, ed. CURRENT Diagnosis \& Treatment Otolaryngology-Head and Neck Surgery. McGraw-Hill Education/Medical; 2019

4 Lee EI. Aesthetic alteration of the chin. Semin Plast Surg 2013;27 (03):155-160

5 Kellman RM. In: Flint PW, et al. eds. Cummings Otolaryngology Head and Neck Surgery E-Book. 3672. Elsevier Health Sciences; 2014

6 Kqiku L, Weiglein AH, Pertl C, Biblekaj R, Städtler P. Histology and intramandibular course of the inferior alveolar nerve. Clin Oral Investig 2011;15(06):1013-1016

7 Guyuron B. MOC-PS(SM) CME article: genioplasty. Plast Reconstr Surg 2008;121(4, Suppl):1-7

8 Ritter EF, Moelleken BR, Mathes SJ, Ousterhout DK. The course of the inferior alveolar neurovascular canal in relation to sliding genioplasty. J Craniofac Surg 1992;3(01):20-24

9 Guyot L, Layoun W, Richard O, Cheynet F, Gola R. Alteration of chin sensibility due to damage of the cutaneous branch of the mylohyoid nerve during genioplasty. J Oral Maxillofac Surg 2002;60 (11):1371-1373

10 Sykes JM, Frodel JL. In: Flint PW, et al. eds. Cummings Otolaryngology - Head and Neck Surgery E-Book. 3672. Elsevier Health Sciences; 2014

11 Travers JB. In: Flint PW, et al. eds. Cummings Otolaryngology Head and Neck Surgery E-Book. 3672. Elsevier Health Sciences; 2014

12 Rubens BC, West RA. Ptosis of the chin and lip incompetence: consequences of lost mentalis muscle support. J Oral Maxillofac Surg 1989;47(04):359-366

13 Zide BM. The mentalis muscle: an essential component of chin and lower lip position. Plast Reconstr Surg 2000;105(03): 1213-1215

14 Sykes JM. Magill CK in Bailey's Head and Neck Surgery (ed Johnson J) 3016. Lippincott Williams \& Wilkins; 2013

15 Rosen HM. Aesthetic refinements in genioplasty: the role of the labiomental fold. Plast Reconstr Surg 1991;88(05):760-767

16 Arroyo HH, Olivetti IP, Lima LF, Jurado JR. Clinical evaluation for chin augmentation: literature review and algorithm proposal. Rev Bras Otorrinolaringol (Engl Ed) 2016;82(05):596-601

17 Ahmed J, Patil S, Jayaraj S. Assessment of the chin in patients undergoing rhinoplasty: what proportion may benefit from chin augmentation? Otolaryngol Head Neck Surg 2010;142(02): 164-168

18 Ricketts RM. Esthetics, environment, and the law of lip relation. Am J Orthod 1968;54(04):272-289

19 Steiner CC. Cephalometrics in clinical practice. Am J Orthod Dentofacial Orthop 1968;54

20 González-Ulloa M. Quantitative principles in cosmetic surgery of the face (profileplasty). Plast Reconstr Surg Transplant Bull 1962; 29:186-198
21 Gibson FB, Calhoun KH. Chin position in profile analysis. Comparison of techniques and introduction of the lower facial triangle. Arch Otolaryngol Head Neck Surg 1992;118(03):273-276

22 Holdaway RA. A soft-tissue cephalometric analysis and its use in orthodontic treatment planning. Part I. Am J Orthod 1983;84(01): $1-28$

23 Merrifield LL. The profile line as an aid in critically evaluating facial esthetics. Am J Orthod 1966;52(11):804-822

24 Binder WJ, Kamer FM, Parkes ML. Mentoplasty-a clinical analysis of alloplastic implants. Laryngoscope 1981;91(03):383-391

25 Louis PJ, Cuzalina LA. Alloplastic augmentation of the face. Atlas Oral Maxillofac Surg Clin North Am 2000;8(02):127-191

26 Semergidis TG, Migliore SA, Sotereanos GC. Alloplastic augmentation of the mandibular angle. J Oral Maxillofac Surg 1996;54 (12):1417-1423

27 Yaremchuk MJ, Doumit G, Thomas MA, Thomas MA. Alloplastic augmentation of the facial skeleton: an occasional adjunct or alternative to orthognathic surgery. Plast Reconstr Surg 2011;127 (05):2021-2030

28 Oliver JD, Eells AC, Saba ES, et al. Alloplastic facial implants: a systematic review and meta-analysis on outcomes and uses in aesthetic and reconstructive plastic surgery. Aesthetic Plast Surg 2019;43(03):625-636

29 Juszczak HM, Fridirici Z, Knott PD, Park AM, Seth R. An update in facial gender confirming surgery. Curr Opin Otolaryngol Head Neck Surg 2019;27(04):243-252

30 Terino EO. Complications and problems in aesthetic plastic surgery (ed Peck G). New York: Gower Medical; 1991

31 Binder WJ. Custom-designed facial implants. Facial Plast Surg Clin North Am 2008;16(01):133-146, vii

32 Goldsmith D, Horowitz A, Orentlicher G. Facial skeletal augmentation using custom facial implants. Atlas Oral Maxillofac Surg Clin North Am 2012;20(01):119-134

33 Al-Jandan B, Marei HF. Mandibular angle augmentation using solid silicone implants. Dent Med Probl 2018;55(04):367-370

34 Terino EO, Edwards MC. Customizing jawlines: the art of alloplastic premandible contouring. Facial Plast Surg Clin North Am 2008;16(01):99-122, vi

35 Yaremchuk MJ. Mandibular augmentation. Plast Reconstr Surg 2000;106(03):697-706

36 Dec W, Warren SM. SJ Aston, DS Steinbrech, J Walden: Aesthetic plastic surgery 423-436 (Elsevier Saunders, 2009)

37 Kadakia S, Cranford J, Ducic Y. Options in Chin Augmentation. Recent Advances in Otolaryngology Head \& Neck Surgery 6, 213219 (2017)

38 Reed EH, Smith RG. Genioplasty: a case for alloplastic chin augmentation. J Oral Maxillofac Surg 2000;58(07):788-793

39 Rojas YA, Sinnott C, Colasante C, Samas J, Reish RG. Facial implants: controversies and criticism. a comprehensive review of the current literature. Plast Reconstr Surg 2018;142(04): 991-999

40 Chang EW, Lam SM, Karen M, Donlevy JL. Sliding genioplasty for correction of chin abnormalities. Arch Facial Plast Surg 2001;3 (01):8-15

41 Alvarez CM, Lessin ME, Gross PD. Mandibular advancement combined with horizontal advancement genioplasty for the treatment of obstructive sleep apnea in an edentulous patient. A case report. Oral Surg Oral Med Oral Pathol 1987;64(04):402-406

$42 \mathrm{Li}$ KK, Cheney ML. The use of sliding genioplasty for treatment of failed chin implants. Laryngoscope 1996;106(3 Pt 1):363-366

43 Jones BM, Vesely MJJ. Osseous genioplasty in facial aesthetic surgery-a personal perspective reviewing 54 patients. J Plast Reconstr Aesthet Surg 2006;59(11):1177-1187

44 Chan D, Ducic Y. A simplified, reliable approach for advancement genioplasty. JAMA Facial Plast Surg 2016;18(02):114-118

45 Hamilton MM, Chan D. Adjunctive procedures to neck rejuvenation. Facial Plast Surg Clin North Am 2014;22(02):231-242 
46 Strauss RA, Abubaker AO. Genioplasty: a case for advancement osteotomy. J Oral Maxillofac Surg 2000;58(07):783-787

47 Frodel JL, Sykes JM, Jones JL. Evaluation and treatment of vertical microgenia. Arch Facial Plast Surg 2004;6(02):111-119

48 Gui L, Huang L, Zhang Z. Genioplasty and chin augmentation with Medpore implants: a report of 650 cases. Aesthetic Plast Surg 2008;32(02):220-226

49 Reddy PS, Kashyap B, Hallur N, Sikkerimath BC. Advancement genioplasty-cephalometric analysis of osseous and soft tissue changes. J Maxillofac Oral Surg 2011;10(04):288-295

50 Shaughnessy S, Mobarak KA, Høgevold HE, Espeland L. Long-term skeletal and soft-tissue responses after advancement genioplasty. Am J Orthod Dentofacial Orthop 2006;130(01):8-17

51 Hendler BH, Costello BJ, Silverstein K, Yen D, Goldberg A. A protocol for uvulopalatopharyngoplasty, mortised genioplasty, and maxillomandibular advancement in patients with obstructive sleep apnea: an analysis of 40 cases. J Oral Maxillofac Surg 2001;59(08):892-897, discussion 898-899

52 Kezirian EJ, Goldberg AN. Hypopharyngeal surgery in obstructive sleep apnea: an evidence-based medicine review. Arch Otolaryngol Head Neck Surg 2006;132(02):206-213

53 Mintz SM, Ettinger AC, Geist JR, Geist RY. Anatomic relationship of the genial tubercles to the dentition as determined by cross-sectional tomography. J Oral Maxillofac Surg 1995;53(11):1324-1326

54 Santos Junior JF, Abrahão M, Gregório LC, Zonato AI, Gumieiro EH. Genioplasty for genioglossus muscle advancement in patients with obstructive sleep apnea-hypopnea syndrome and mandibular retrognathia. Rev Bras Otorrinolaringol (Engl Ed) 2007;73 (04):480-486

55 de Santana Santos T, Albuquerque KM, Santos MESM, Laureano Filho JR. Survey on complications of orthognathic surgery among oral and maxillofacial surgeons. J Craniofac Surg 2012;23(05): e423-e430

56 Bruno Carlo B, Mauro P, Silvia B, Enrico S. Modified genioplasty and bimaxillary advancement for treating obstructive sleep apnea syndrome. J Oral Maxillofac Surg 2008;66(09): 1971-1974

57 Ousterhout DK. Sliding genioplasty, avoiding mental nerve injuries. J Craniofac Surg 1996;7(04):297-298

58 Reyneke JP, Sullivan SM. A simplified technique of genioplasty with simultaneous widening or narrowing of the chin. J Oral Maxillofac Surg 2001;59(10):1244-1245

59 Shaik M, Koteswar Rao N, Kiran Kumar N, Prasanthi G. Comparison of rigid and semirigid fixation for advancement genioplasty. J Maxillofac Oral Surg 2013;12(03):260-265

60 Triaca A, Furrer T, Minoretti R. Chin shield osteotomy-a new genioplasty technique avoiding a deep mento-labial fold in order to increase the labial competence. Int J Oral Maxillofac Surg 2009; 38(11):1201-1205

61 Wang J, Gui L, Xu Q, Cai J. The sagittal curving osteotomy: a modified technique for advancement genioplasty. J Plast Reconstr Aesthet Surg 2007;60(02):119-124 